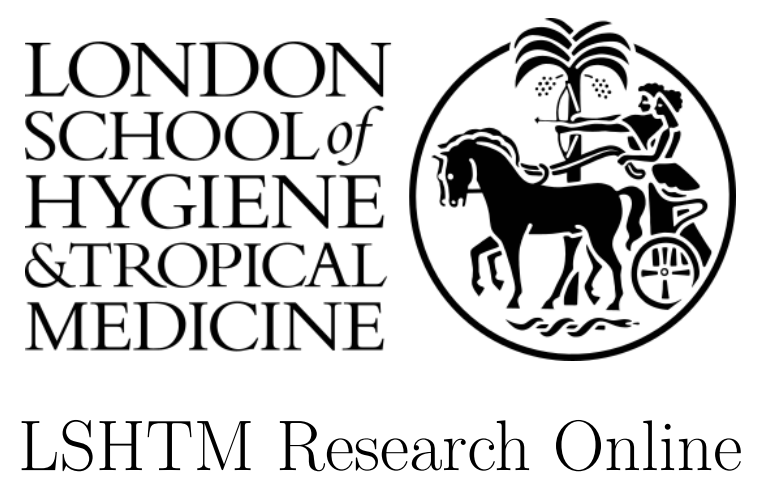

Paltiel, Ora; Berhe, Ephrem; Aberha, Amanuel Haile; Tequare, Mengistu Hagazi; Balabanova, Dina; (2020) A public-private partnership for dialysis provision in Ethiopia: a model for high-cost care in low-resource settings. Health policy and planning, 35 (9). pp. 1262-1267. ISSN 0268-1080 DOI: https://doi.org/10.1093/heapol/czaa085

Downloaded from: https://researchonline.lshtm.ac.uk/id/eprint/4657929/

DOI: https://doi.org/10.1093/heapol/czaa085

Usage Guidelines:

Please refer to usage guidelines at https://researchonline.lshtm.ac.uk/policies.html or alternatively contact researchonline@lshtm.ac.uk.

Available under license. To note, 3rd party material is not necessarily covered under this license: Copyright the publishers 


\section{A public-private partnership for dialysis provision in Ethiopia: a model for high-cost care}

in low-resource settings?

\section{Key messages:}

Private-public partnerships (PPPs) to provide high-cost care have been advocated in low resource settings but evidence on what contributes to making these partnerships successful and sustainable is mixed.

Ethiopia, like many low-income countries, struggles with a double burden of infectious and non-communicable diseases and has inadequate resources to provide renal replacement therapy to all who require it.

This PPP in a peripheral hospital in Northern Ethiopia grew out of an ethical commitment to provide haemodialysis and has succeeded in providing continuous service for 6 years to patients with acute and chronic kidney failure.

Besides contractual elements, we identify local leadership, community and institutional support, as key elements in the PPP's continued success, despite ongoing challenges and threats to sustainability. 


\section{Abstract:}

Our purpose was to explore whether private-public partnership (PPPs) can serve as a model for access to high-cost care in low resource settings by examining a unique PPP providing haemodialysis services in a remote setting in Northern Ethiopia, investigating challenges and enablers.

The study setting is a 500-bed teaching hospital serving a catchment population of 8 million in Northern Ethiopia. Based on local data collection, observation and in-depth interviews, we identified the impetus for the PPP, describe the partnership agreement, report outcomes after six years of activity, and examine challenges that have arisen since the program's inception, including funding sustainability.

The PPP was established in 2013 based on a decision by local leadership that treatment of patients with acute kidney injury is a necessity rather than a luxury. A private partner was sought who could ensure service delivery as well as a reliable supply of consumables. The hospital contributions included infrastructure, personnel and sharing of maintenance costs. The partnership has facilitated uninterrupted haemodialysis service to 101 patients with acute kidney injury and 202 with chronic kidney disease. The former ( $>50 \%$ cured) were mainly supported by charitable donations procured by the hospital's leadership, while the latter were self-funded. The local university and community contributed to the charity. Utilization has increased yearly. Funding and logistical issues remain.

In conclusion, this PPP enabled access to previously unavailable lifesaving care in Northern Ethiopia and could serve as a model for potential scale-up for haemodialysis provision in particular, and more broadly, high-cost care in low-resource settings. An ethical commitment to provide the service, combined with ongoing administrative and community 
involvement has contributed to its sustained success. Lack of affordability for most patients requiring chronic haemodialysis and reliance on charitable donations for treatment of patients with acute kidney injury pose challenges to long-term sustainability. 


\section{Introduction}

Provision of high-cost care in low-resource settings poses ethical, financial and logistical challenges. There is an emerging debate whether low-and middle-income countries should cover costly treatments in the progressive realization of the "right to health" (Argent, 2018). Health system strengthening in low-and middle-income countries usually focuses on primary and preventive services (WHO Report, 2008; De Sa, 1993). Public systems are often inadequately funded and equipped to manage the increasing burden of non-communicable diseases. One possible strategy is to forge public-private partnerships (PPPs) sharing risks and resources for high-cost services (Jomo et al., 2016).

Evidence regarding what makes PPPs successful is inconclusive. A systematic review of $>1400$ sources revealed knowledge gaps including incomplete reporting, limited longitudinal assessment of clinical and value-for-money outcomes, and scanty analysis of policy and practice implications (Roehrich et al., 2014). Reports frequently focus on contracting, accounting, and risk transfer, rarely on the roles of leadership and community support in the long-term success and transferability of PPPs.

Chronic Kidney Disease (CKD) and Acute Kidney Injury (AKI) pose substantial societal burdens, especially in low income countries (Bello et al., 2018). Renal replacement therapy (RRT), comprising transplantation, peritoneal and haemodialysis, represents the standardof-care for CKD and AKI. Haemodialysisrequires a skilled workforce, expensive permanent equipment and reliable supplies of consumables, the latter representing the highest direct expense in low income countriess (Ranasinghe et al., 2011; Kaur et al., 2018). Even temporary shortages can be disruptive, with dire consequences for patients. 
Besides resource availability, political factors and advocacy play major roles in determining RRT accessibility in both high and low-and middle-income countries (Hull, 1997; Barsoum, 2006; USRDS, 2018). In Thailand, RRT was initially excluded from the 2002 universal health package. However, arguments by nephrologists, families and patients that CKD causes catastrophic expenditure and long-term financial burden, led to RRT's inclusion (Chuengsaman and Kasemsup, 2017). This widely-reported experience has fostered global debate, often polarized, on provision of high-cost care among countries committed to universal health coverage (Teerawattananon et al., 2016; Angell and Jha, 2018).

In sub-Saharan Africa, a double encumbrance of rising non-communicable diseases coupled with persistent infectious and perinatal morbidities contribute to high incidence and mortality rates for CKD and AKI (Stanifer et al., 2014; Ashuntantang et al., 2017; Kaze et al., 2018). The region has limited capacity to provide RRT (Htay et al., 2018); only 9-16\% of those requiring RRT actually receiving services (Okpechi, 2017), the vast majority paying outof-pocket (Bello et al., 2017). Besides limiting access to those who can pay (Bello et al., 2013), compromises have included restricting publicly-funded dialysis to patients eligible for renal transplantation (Etheredge and Fabian, 2017), curtailing the total number of treatments for AKI (Tuso, 2009) or limiting dialysis duration/frequency (Ashuntantang et al., 2017). Many patients forgo or abandon treatment for financial reasons (Ashuntantang et al., 2017).

Ethiopia spends only 5\% of its gross domestic product on healthcare and is a major recipient of external healthcare aid, mainly supporting communicable disease control and government-run primary care. RRT has been funded by sporadic charitable donations (Berman et al., 2018). Although CKD and AKI are common causes of hospitalization (Riley et 
al., 2013; Adugna et al., 2018) and up to 9\% of deaths (Abera et al., 2017), resources and trained nephrologists are lacking to treat most Ethiopians requiring RRT (Bello et al., 2017).

Private haemodialysis facilities opened in Ethiopia's capital, Addis Ababa, in the early 2000s (Shibiru et al., 2013) and the first public unit in 2013 (Ibrahim et al., 2016). Individuals from peripheral regions could not access RRT. The cost-per-dialysis-session in private hospitals of US\$68-100 (Tuso, 2009; Luyckx et al., 2017) represents >one-tenth the average annual wage for farmers ( $80 \%$ of the population). Perceived as a treatment "for the rich" (Shibiru et al., 2013), few can afford to adhere to haemodialysis and required medications (Kefale et al., 2018). Patients requiring dialysis frequently rely on relatives, often those living abroad, for assistance.

PPPs are seen as potential solutions to RRT access in sub-Saharan Africa (Okpechi, 2017), however, empirical evidence of their effectiveness and applicability is scarce. We undertook a critical examination of a unique PPP, established to provide haemodialysis in a public hospital in northern Ethiopia, based on utilization data, interviews and observation. Extending a preliminary 2015 assessment (MoH HEPCAPS2 Project, 2015), we describe the PPP's structure, outcomes, challenges and enablers, identifying issues relevant to scaling-up dialysis services in Ethiopia and otherlow-middle income countries.

\section{Public-private partnership description}

Setting, structure and funding model: The PPP was established in the author's hospital (AH), a 500-bed university hospital serving a catchment population of 8 million. RRT was unavailable locally until 2013. The decision to provide haemodialysis was made by senior physicians who concluded that the service should be considered a necessity rather than a 
luxury, especially for AKIAKI was identified as a target condition, since it is often reversible following appropriate short term treatment with relatively few dialysis sessions and often strikes young patients(Ashuntantang et al., 2017). This early strategic decision provided a coherent framework for subsequent actions.

The next step was to identify a feasible service-delivery model. The option of relying on the public system, with $\mathrm{AH}$ itself delivering the service and contracting with individual suppliers, was rejected due to frequent foreseen shortages of consumables. Previous open bids for other services had been ineffective, with supply chain interruptions and canceled deliveries for various reasons, including foreign currency shortages.

Accordingly, the hospital administration-with the local University's support-proposed a PPP model. The objective was to provide reliable haemodialysis access while providing the bidding company a modest profit incentive. The administration identified a Sudanese company (M), already providing services in a private hospital in Addis. The bid was noncompetitive due to a paucity of candidates willing and able to provide high-cost services in remote regions. Despite apprehension that it would be unwilling to partner with a peripheral government hospital, M committed to procuring and delivering supplies using its own foreign currency on-time, in the expectation that profit would accrue from out-ofpocket payments for haemodialysis.

The Hemodialysis service was thus launched in 2013 based on a 10-year renewable agreement between $\mathrm{AH}$, the University and $\mathrm{M}$. The main PPP components are described in Table 1 . The current unit, staffed by 11 trained dialysis nurses, a general practitioner, a doctor responsible for vascular catheterization (all hospital employees) and support staff, operates five functional dialysis machines for two daily sessions. The unit is supervised by 
the hospital's director who is responsible for staffing and recruitment, logistics (ensuring water treatment safety, power supply, maintenance and repair services), and confirming eligibility for the charitable Kidney Fund (see below).

AH did not seek a profit, with all savings mobilized to reduce patient costs. Thegoal was to provide access to dialysis for the hospital's entire catchment population in the region and not just the city, while demonstrating to Ethiopian policymakers and hospital administrators the feasibility of supporting high-cost services even in remote areas. Dialysis sessions were priced at $80 \%$ that charged by private hospitals in Addis (1,250 Ethiopian birrs [EHB] US \$ Hence the cost for two hemodialysis sessions per week, will be $\$ 3636.36$ USD per year per patient, which represents over four times the average annual income in Ethiopia )(Ethiopia Income). The hospital reserved the right to waive fees in some cases while maintaining the spirit of the PPP agreement.

Process, utilization and outcomes:

The dialysis service operates as per international guidelines: water quality is monitored, monthly urea-reduction ratios measured, and a registry kept. Patients are weighed pre- and post-session to assess inter-dialytic weight gain and dry weight. Relevant medications (erythropoietin, intravenous iron, calcium-based phosphate binders and vitamins) are purchased by CKD patients from private pharmacies. AH has invested in capacity-building by sending three physicians abroad for one-year nephrology specialty training.

Between 2013 and 2019, 323 patients were dialyzed at the center, of whom 101 (31\%) suffered from AKI and 222 from CKD. Utilization has increased annually (Figure 1). Currently, 23 CKD patients undergo twice-weekly haemodialysis. CKD patients are self-funded, while 
$90 \%$ of the AKI patients were subsidized by charitable donations. Service provision has been uninterrupted except for seven days in 2018, when M temporarily lacked foreign currency for consumables. Over half of treated AKI patients recovered (Figure 2). Those who do not recover are offered chronic hemodialysis, which must be paid for out-of-pocket.

Challenges and enablers:

The 2015 report (MoH HEPCAPS2 Project, 2015), compiled after only 49 patients had been treated, noted that the PPP's benefits included access to a service previously unavailable or requiring long $(760 \mathrm{~km})$ travel. Problems cited included underuse, lack of profitability and a perception that, although cheaper than the average Ethiopian price, haemodialysis remained too expensive for most chronic patients. The report made three recommendations, which have been partially implemented: 1) promotion of the program and establishing referral linkages with nearby health facilities in order to increase utilization; 2) tax exemption to help reduce patient fees, while maintaining revenue to the facility, and 3) scale-up to other regions.

As noted, underuse is no longer a problem. However, there are still patients in the region, whose numbers are unknown, who are undiagnosed, not referred, or unable to access services due to lack of funds, and are thus likely to die of kidney disease. Thus equity remains an issue. The program is widely publicized in the community, which has been engaged in philanthropic support. At least four other public hospitals in Ethiopia have followed AH's example and launched haemodialysis services. PPP as a concept is endorsed in Ethiopia's 2015-2020 Health Sector Transformation plan (Ethiopia Ministry of Health, 2015). 
Challenges have arisen, including unforeseen costs, logistical and ethical issues. Frequent power failures necessitated installation of a separate back-up generator (hospital-funded). To ensure ongoing equipment maintenance, $\mathrm{AH}$ elected to cover airfare, food and lodging to bring a biomedical engineer from the capital, a cost-sharing gesture which fostered good relationships with $\mathrm{M}$.

Ethical problems arose when patients and families (specifically, parents of children with AKI) became aware that haemodialysis services existed but were unaffordable. A model was required to provide pro bono dialysis, without financially harming the private partner and endangering the partnership. To this end a charitable fund for financially needy (confirmed by their local community authority) "good prognosis" AKI patients (determined by two senior physicians) was established with contributions from the University $(500,000 \mathrm{EHB}$ US\$18,500), and by private Ethiopian donors $(45,000 \mathrm{EHB})$. These donations enabled access to life-saving dialysis for $90 \%$ of the 101 AKI patients without disrupting the PPP. After a few years, the hospital contributed $>500,000$ EHB from its limited internal revenue to replenish the diminishing fund.

Long-term funding has proven more challenging. In order to continue service provision for needy AKI patients, the hospital launched a fund to which citizens can contribute using an earmarked bank account, as well as approaching other potential sources. AH recently received a donation of 12 haemodialysis machines with an advanced water treatment plant, hence is negotiating with $\mathrm{M}$ to lower costs to $900 \mathrm{EHB} /$ session, rendering the service more affordable to CKD patients. The challenge of financing haemodialysis for patients with CKD remains. Tragically, some patients who do not recover from AKI cannot afford ongoing 
haemodialysis once their situation becomes chronic, and have succumbed to their disease (numbers unknown). Long term sustainability will likely require government support.

\section{Analysis}

Precedents for PPPs providing renal replacement therapy. The case for PPPs to enhance healthcare delivery in settings where the public sector is unable to provide reliable services is persuasive (Roehrich et al., 2014). PPPs have been utilized to provide haemodialysis worldwide: for example, a German company, using a range of public and private funding mechanisms, provides dialysis in 50 countries (Fresenius medical care, 2019), including LOW INCOME COUNTRIES, such as Swaziland (Serving patients in Swaziland-Fresenius Medical Care).

While some evidence exists regarding their contribution to improved quality and access of care in low-and middle-income countries, PPPs are not a panacea. The well-known example from Lesotho provided mixed results: improved access to services, drug accountability, decreased absenteeism and reduced mortality for some conditions were accompanied by increased costs, caesarian-section rates and service demands (McIntosh et al., 2015; Vian et al., 2015). Lesotho's PPP was implemented simultaneously with accreditation procedures to monitor quality, making it difficult to assess its sole effects (Hellowell, 2019). Resources provided were insufficient to monitor, administer and fund the services, hampering sustainability (Hellowell, 2019).

"Bottom-up" initiation of the PPP in Ethiopia: The PPP described herein is the first of its kind for haemodialysis provision among peripheral hospitals in Ethiopia. The impetus for it came 
from the hospital itself, in contrast with the usual centrally-driven strategies both in Ethiopia and beyond Contractual negotiations were decentralized, requiring hands-on involvement of the hospital leadership. Local circumstances (eg. the identification of AKI-treatment as an ethical obligation, establishing a charity) enabled both the PPP's establishment and sustainability for $>6$ years.

Involvement of hospital leadership: One salient aspect of this PPP is AH's leadership's commitment to providing uninterrupted haemodialysis service. This has necessitated flexibility regarding cost-sharing, eliciting support from the University, public engagement, and maintaining collaborative relationships both with the private partner and with national government officials to ensure supply of consumables with minimal bureaucracy. As noted by Gallouz and colleagues, "maintaining a balanced mix of private and public-sector principles within a PPP... requires solid project management and leaders with strong relational and interpersonal skills who are able to establish a climate of trust"(Gallouj et al., 2010). The AH example appears to have achieved this goal and may serve as a model for providing resource-intense care in Ethiopia's periphery (the hospital is now considering a PPP for provision of reproductive technologies), as well as otherlow income countries; but success will require continual investment and involvement of hospital leaders.

Ongoing challenges: sustainability and equity: Notwithstanding the noted achievements, reliance on philanthropy to provide the service for which the facility was established (dialysis for AKI), and the lack of affordability of chronic haemodialysis raise questions regarding sustainability and equity. Systematic surveys of the catchment area are required to provide a true estimate of dialysis needs in the future. Furthermore, dependence on the private partner's foreign currency to supply consumables unavailable locally, and M's cross- 
border headquarters (in a country which itself has become politically unstable), potentially threaten the consistency of supplies and service. These factors underscore the necessity of regional political agreements to ensure stability of PPPs(United Nations Economic Commission for Europe. Governance in Public Private Partnerships for Infrastructure Development, 2004).

\section{Conclusion}

Universal health coverage has been set as a worldwide goal, and increasingly, high-cost treatments such as RRT are considered for inclusion (Harris et al., 2019). The ideal of universally accessible and publicly-funded RRT is still a long way off for most low-income countries, where the need for this service is already great and likely to rise substantially in the coming decades. The described PPP for haemodialysis provision in a peripheral Ethiopian hospital offers a unique example of a response to an identified need. In the absence of government support and while awaiting inclusion of renal replacement therapy in Ethiopia's universal health package this PPP can be viewed as an instructive local initiative. The prioritization of AKI treatment, the ethical commitment to provide resourceintense care to serve the community's needs and the broad stakeholder involvement to ensure its realization are principles which should be applicable elsewhere.

PPPs can contribute to care delivery, but to succeed, will require continued engagement of health care leadership, monitoring and strategies for sustainable funding. Globally, enhanced prevention is required, alongside creative solutions, including PPPs, to ensure efficient and equitable care for patients with kidney disease and other chronic conditions.

\section{$\underline{\text { References }}$}

Abera SF, Gebru AA, Biesalski HK, et al. 2017. Social determinants of adult mortality from 
non-communicable diseases in northern Ethiopia, 2009-2015: Evidence from health and demographic surveillance site. PLoS ONE 12: e0188968.

Adugna T, Merga H, Gudina EK. 2018. Impaired glomerular filtration rate, high grade albuminuria and associated factors among adult patients admitted to tertiary Hospital in Ethiopia. BMC Nephrology 19: 345.

Angell B, Jha V. 2018. Universal Care for Kidney Diseases: Sustainable Development or Path to Financial Ruin? Kidney International Reports 4: 361-4.

Argent AC. 2018. Considerations for Assessing the Appropriateness of High-Cost Pediatric Care in Low-Income Regions. Frontiers in Pediatrics 6: 68.

Ashuntantang G, Osafo C, Olowu WA, et al. 2017. Outcomes in adults and children with endstage kidney disease requiring dialysis in sub-Saharan Africa: a systematic review. The Lancet Global Health 5: e408-17.

Barsoum RS. 2006. Chronic Kidney Disease in the Developing World. New England Journal of Medicine 354: 997-9.

Bello AK, Alrukhaimi M, Ashuntantang GE, et al. 2018. Global overview of health systems oversight and financing for kidney care. Kidney International Supplements 8: 41-51.

Bello AK, Levin A, Tonelli M, et al. 2017. Assessment of global kidney health care status. JAMA - Journal of the American Medical Association 317: 1864-81.

Bello BT, Raji YR, Sanusi I, Braimoh RW, Amira OC, Mabayoje OM. 2013. Challenges of providing maintenance hemodialysis in a resource poor country: Experience from a single teaching hospital in Lagos, Southwest Nigeria. Hemodialysis International 17: 427-33.

Berman P, Mann C, Ricculli ML. 2018. Can Ethiopia finance the continued development of its primary health care system if external resources decline? Health Systems and Reform 4: 227-38.

Chuengsaman P, Kasemsup V. 2017. PD First Policy: Thailand's Response to the Challenge of Meeting the Needs of Patients With End-Stage Renal Disease. Seminars in Nephrology 37: 287-95.

Etheredge H, Fabian J. 2017. Challenges in Expanding Access to Dialysis in South AfricaExpensive Modalities, Cost Constraints and Human Rights. Healthcare 5: pii.E38.

Ethiopia - Income. https://www.nationsencyclopedia.com/Africa/Ethiopia-INCOME.html. Accessed June 08, 2020

Fresenius Medical Care-The health care group. https://www.fresenius.com/freseniusmedical-care. Accessed January 13, 2020

Gallouj F, Merlin-Brogniart C, Provost A-C. 2010. Public-private partnerships in hospital innovation: what lessons for hospital management? Research Report. University Lille 1 , CLERSE. 
Harris D, Davies S, Finkelstein F, et al. 2019. Increasing access to integrated ESKD care as part of universal health coverage. Kidney International 95: s1-33.

Hellowell M. 2019. Are public-private partnerships the future of healthcare delivery in subSaharan Africa? Lessons from Lesotho. BMJ Global Health 4: ee001217.

Htay H, Alrukhaimi M, Ashuntantang GE, et al. 2018. Global access of patients with kidney disease to health technologies and medications: findings from the Global Kidney Health Atlas project. Kidney International Supplements 8: 64-73.

Hull A. 1997. The legislative and regulatory process in the end-stage renal disease (ESRD) program, 1973 through 1997. Seminars in Nephrology 17: 160-9.

Ibrahim A, Ahmed MM, Kedir S, Bekele D. 2016. Clinical profile and outcome of patients with acute kidney injury requiring dialysis - An experience from a haemodialysis unit in a developing country. BMC Nephrology 17: 91.

Jomo K, Chowdhury A, Sharma K, D P. 2016. Public-Private Partnerships and the 2030 Agenda for Sustainable Development: Fit for purpose?DESA Working Paper No. 148

Kaur G, Prinja S, Ramachandran R, Malhotra P, Gupta KL, Jha V. 2018. Cost of hemodialysis in a public sector tertiary hospital of India. Clinical Kidney Journal 11: 726-33.

Kaze AD, Ilori T, Jaar BG, Echouffo-Tcheugui JB. 2018. Burden of chronic kidney disease on the African continent: A systematic review and meta-analysis. BMC Nephrology 19: 125.

Kefale B, Tadesse Y, Alebachew M, Engidawork E. 2018. Management practice, and adherence and its contributing factors among patients with chronic kidney disease at Tikur Anbessa Specialized Hospital: A hospital-based cross-sectional study. PLOS ONE 13: e0200415.

Luyckx VA, Miljeteig I, Ejigu AM, Moosa MR. 2017. Ethical Challenges in the Provision of Dialysis in Resource-Constrained Environments. Seminars in Nephrology 37: 273-86.

McIntosh N, Grabowski A, Jack B, Nkabane-Nkholongo EL, Vian T. 2015. A public-private partnership improves clinical performance in a hospital network in Lesotho. Health Affairs 34: 954-62.

MoH, HEPCAPS2 Project. 2015. Strengthening Public Private Partnerships for More and Better Health Outcomes in Ethiopia: Expert Reviews and Case Studies. Ethiopian Ministry of Health, Harvard T.H. Chan School of Public Health, JSI Research \& Training Insti. 2015. : 91.

Okpechi IG. 2017. ESKD in sub-Saharan Africa: will governments now listen? The Lancet Global Health 5: e373-4.

Ranasinghe P, Perera YS, Makarim MFM, Wijesinghe A, Wanigasuriya K. 2011. The costs in provision of haemodialysis in a developing country: A multi-centered study. BMC Nephrology 12: 42.

Riley S, Diro E, Batchelor P, et al. 2013. Renal impairment among acute hospital admissions 
in a rural Ethiopian hospital. Nephrology 18: 92-6.

Roehrich JK, Lewis MA, George G. 2014. Are public-private partnerships a healthy option? A systematic literature review. Social Science and Medicine 113: 110-9.

De Sa C. 1993. The preventive-curative conflict in primary health care. Health for the millions 1: 14-7.

Serving patients in Swaziland-Fresenius Medical care. https://www.fresenius.com/servingpatients-in-swaziland. Accessed January 13, 2020

Shibiru T, Gudina EK, Habte B, Derbew A, Agonafer T. 2013. Survival patterns of patients on maintenance hemodialysis for end stage renal disease in Ethiopia: Summary of 91 cases. BMC Nephrology 14: 127.

Stanifer JW, Jing B, Tolan S, et al. 2014. The epidemiology of chronic kidney disease in subSaharan Africa: A systematic review and meta-analysis. The Lancet Global Health 2: e174-81.

Teerawattananon Y, Luz A, Pilasant S, et al. 2016. How to meet the demand for good quality renal dialysis as part of universal health coverage in resource-limited settings? Health Research Policy and Systems 14: 21.

The Federal Democratic Republic of Ethiopia Ministry of Health. HSTP, Health Sector Transformation Plan. 2015. https://www.globalfinancingfacility.org/sites/gff_new/files/Ethiopia-health-systemtransformation-plan.pdf. Published 2015. Accessed January 13, 2020.

The World Health Report 2008 - primary Health Care. https://www.who.int/whr/2008/en/. Accessed January 13, 2020.

Tuso P. 2009. SERVE Ethiopia. The Permanente Journal 13: 51-64.

United Nations Economic Commission for Europe. Governance in Public Private Partnerships for Infrastructure Development. 2004.

https://www.unece.org/fileadmin/DAM/ie/ppp/documents/botguidegov.pdf.Accessed June 08, 2020

USRDS. 2018. Chapter 9 Health Care Expenditures for persons with ESRD. 71: s433-440.

Vian T, Mclntosh N, Grabowski A, Nkabane-Nkholongo EL, Jack BW. 2015. Hospital PublicPrivate Partnerships in Low Resource Settings: Perceptions of How the Lesotho PPP Transformed Management Systems and Performance. Health Systems and Reform 1: 155-66. 